\title{
A depression screening day for the elderly in a general practice setting
}

\author{
Walter Forbes, Diana E. Tracy, Ross J. Hamilton and John M. Eagles
}

\begin{abstract}
Unrecognised and untreated deprestion ts common, particulaty in the elderty. This paper describes an attempt to ofter screening for deprestion to 4,500 people over the age of 60 . Only two people attended and both were depressed. This may hove related to the arrangements for screening. to the symptoms of depression, to inadequate publictly or to characteristics of the elderty population. Others contemplating screening for deprescion in eldety populations are advised to adopt a difterent methodology.
\end{abstract}

Over the last three years in the United States of America there has been a National Depression Day which has attracted many thousands of participants with over $75 \%$ of those screened scoring positive for depression. In response to the Royal College of Psychiatrists' and Royal College of General Practitioners' Defeat Depression Campaign and to coincide with National Mental Health Week in October 1993, we organised a depression screening day in a local health centre. This was a pilot study and, as it was the European Year of the Elderly and to synchronise with the highlighting of the depressed elderly in the Defeat Depression Campaign, an over $60 \mathrm{~s}$ population was selected. The method was designed to mirror that of National Depression Screening Day in the USA.

\section{The study}

All general practitioners at the five non-fundholding group practices at a large local health centre were contacted and agreed to the screening proposals. From the total patient population of 29,000 , approximately 4.500 were aged over 60 , and these patients were invited to attend to be screened for depression. Publicising of the screening day was by posters displayed in local chemists, post offices, small shops, libraries and the health centre itself, local television coverage and an article in a local newspaper.

The screening tool used was the Hospital Anxiety and Depression Scale (HADS) (Zigmond \& Snaith, 1983). Patients completed this scale prior to a psychiatric interview with one of three psychiatric registrars/SHOs. A consultant was available for supervision and advice. The screening doctors were present on the screening day from 8.00 a.m. until 8.00 p.m., extending the normal opening times of the health centre to enhance access and availability.

\section{Findings}

Two people attended for screening. One (Patient A) was aged 62 and attended in response to the newspaper article. The other (Patient B) was in fact aged only 41 and was referred by her GP from morning surgery. Both patients were 'cases' on the anxiety and the depression subscales of the HADS, and a diagnosis of depressive illness was made in both cases at the subsequent interview. Both were already attending their GP with diagnosed depression and Patient $A$ was taking a tricyclic antidepressant. Neither was a current psychiatric out-patient.

\section{Comment}

There is wide concern about the number of undetected cases of depression in the community and specifically about the rate of suicide, the reduction of which is an aim of the White Paper on the Health of the Nation. Clearly, early detection and treatment of depressive illness could contribute to lowering suicide rates and to a heaithier and more productive population. 
Screening for depression satisfies eight of the nine criteria for a rational screening programme (Wilson \& Jungner, 1968). The unsatisfied criterion was that the cost of case finding through screening should be economically balanced in relation to possible expenditure on medical care as a whole.

In this population of 4,500 over $60 \mathrm{~s}$, at an estimated rate of depression of $13 \%$ (Lindesay et al, 1989), we anticipated that there would be 625 patients with depressive illness. While two-thirds of these patients may be in touch with services, there should be at least 200 with undetected and untreated depression.

Perhaps the publicising of the screening day was inadequate. The newspaper article was printed the week before and the television coverage did not specify the precise screening arrangements. In acquiring more publicity, more use could perhaps have been made of voluntary organisations, health visitors and those in regular contact with the elderly.

But the result of this initiative was clearly disappointing, especially in comparison with the success of National Depression Screening Day in the USA. Its use may be in demonstrating that this method is unsuccessful in this age group. Whether a successful method in the USA can be successfully transposed to a possibly more reclustve population in a different health care system remains to be seen.

In the elderly the effects of depression, such as anergla, poor concentration and social withdrawal, along with poor mobility, make it less likely that they will notice advertising and that, if they did, they could be less able or motivated to attend. Perhaps screening for undetected depression in an older population is best done by GPs, nurses and health visitors, either on an opportunistic basis or as part of the mandatory yearly assessment of the over 75s.

\section{Acknowiedgements}

The authors are grateful to Drs H. R. Millar, P. C. Olley and I. C. Reid for help in planning and conducting the Screening Day, and to Mrs P. McGarrol. We thank all general practitioners and their teams at Denburn Health Centre for allowing us access to their patients and their premises.

\section{References}

LANDESAY, J. BRugGs, K. \& MURPHY, E. (1989) The Guy's/Age Concern Survey: prevalence rates of cognittve impairment. Depression and anxdety in an urban community. Brttish Journal of Psychiatry. 185, 317329.

WIISON. J. M. G \& JUNGner, E. (1968) Princtples and Practice of Screening for Disease. Public Health Papers, No 34. Geneva: World Health Organtration.

ZiGmond, A. S. \& SNwTH, R P. (1983) The Hospital Anxdety and Depression Scale. Acta Psychiatrica Scandinautica. 67. 361-370.

Walter Forbes, Senior House Officer, Diana E. Tracy, Registrar in Psychiatry: Ross J. Hamilton, Registrar in Psychiatry: and, John M. Eagles, Consultant Psychiatrist, Ross Clinic, Royal Cornhill Hospital, Cornhill Road, Aberdeen AB9 22H

*Correspondence 